authoritative workers in the field, a sound study methodology, and a sensitive presentation of the findings in future bulletins.

Furthermore, it is not in the best interest of either patients or the profession to have a service which has no impact on patients' health, and we recognise the responsibility of the medical profession to undertake detailed assessment of any emerging technologies. The service in South Tees Health Authority must therefore be subjected to audit to determine outcomes for patients and to develop guidelines for the users.

The purchasing authorities want value for money, but obtaining outcomes data has resource requirements. Now the issue has been raised there is an onus on the Department of Health to complete the investigation into the use of bone densitometry.

$$
\begin{array}{r}
\text { J N FORDHAM } \\
\text { South Cleveland Hospital, } \\
\text { Middlesbrough, } \\
\text { Cleveland } \\
T S 43 B W
\end{array}
$$

R MADHOK alth Authority, Middlesbrough

1 School of Public Health, University of Leeds; Centre for Health Economics, University of York; Research Unit, Royal College of Physicians; Department of Health. Screening for osteoporosis to prevent fractures. Leeds: University of Leeds, 1992. (Effective Health Care, bulletin No 1.)

2 Johnston CC, Melton LJ, Lindsay R, Eddy AM. Clinical indications for bone mass measurements. A report from the Scientific Advisory Board of the National Osteoporosis
Foundation. 7 Bone Miner Res 1989;4 suppl 2 .

3 Hutchinson A, Polansky SM, Feinstein AR. Post-menopausal oestrogens protect against fractures of the hip and distal radius. A casecontrol study. Lancet 1979;ii:705-9.

AUTHORS' REPLY - Each Effective Health Care bulletin focuses on a key purchasing question about which there is a perceived need for rational information and aims at providing that information in an accurate, concise, and accessible form for clinical and non-clinical decision makers. Of necessity, the bulletins are very focused, presenting only a distillation of the material that the research team reviews. Inevitably, some people who work in the field will feel that the subject has not been comprehensively covered. For example, we did not consider antiresorptive therapy because the bulletin was about population screening to identify women at high risk. The bisphosphonates have been shown to be effective only in reducing the rate of vertebral fracture in women with established osteoporosis. ${ }^{12}$ There is as yet no evidence that they reduce fractures in healthy patients thought to be at risk of osteoporosis, and they are not licensed for this purpose.

The bulletin concentrated on hip fractures because they are associated with a high mortality, considerable morbidity, and considerable cost to the NHS. Vertebral fractures, though more common, are less well understood and are often asymptomatic. We should have included more information on wrist fractures, though our conclusions would not have been significantly affected.

Though it would have been interesting to discuss the effectiveness of bone scanning and treatment for women with risk factors such as early menopause, this is not part of population bone screening. We made this clear in the bulletin, and we did not review the evidence for this practice.

Drs Fordham and Madhok are no doubt aware that case-control studies have major biases which can overestimate the effectiveness of treatments. For example, screening for breast cancer, which has been shown by randomised controlled trials to reduce risk of death by around $30 \%$, is estimated by case-control studies to reduce risk by $50-70 \% .^{3}$ This problem, combined with the evidence we referred to indicating that benefits may diminish after therapy has ceased ${ }^{4}$ but before the period of highest fracture incidence, makes the evidence of long term effectiveness of hormone replacement therapy in preventing fractures less than compelling.

It is also crucial that a screening programme is based on a test that is good at identifying those women most able to benefit from the treatment. The fact that bone density measurement is the only predictor we have at present is irrelevant. On the other hand, compliance is crucial: "The success of any primary screening programme is ultimately dependent on the at-risk population complying with a regimen."

The claim by Drs Fordham and Madhok that population bone screening is not an issue is incorrect. Understandably, there is considerable interest in such programmes, fuelled by advice in women's magazines and from some clinicians and pressure from drug companies. For example, a statement from the director of the Guy's Hospital osteoporosis screening unit (and a member of the National Osteoporosis Society's council of management) says: "It therefore seems reasonable to suggest that all women should have a bone mass measurement, ideally at the time of the menopause ... Those $30 \%$ who have the lowest bone mass in the population should be advised to consider HRT." ${ }^{\circ}$ Professor Nordin, a former director of the MRC Mineral Metabolism Unit, in a statement to the Yorkshire Post on 21 May, called for mass bone screening, and some health authorities have started pilot population bone screening programmes. ${ }^{7}$

Screening often seems an attractive option for preventing disease; only rarely, however, have initial hopes been justified, most are relatively ineffective and cause unnecessary anxiety. ${ }^{8}$ Therefore it is essential that population bone screening (which would result in over a quarter of well women aged over 50 being recommended long term treatment) is thoroughly evaluated before it is introduced. Audit is no refuge from these questions which can only be answered by scientifically conducted trials of the programme or at least its constituent parts. Cohorts in the Hull and Aberdeen studies have only recently been recruited, and it will be several years before the effectiveness of the bone screening programmes can be reliably estimated.

$$
\begin{array}{r}
\text { TREVOR A SHELDON } \\
\text { for the Effective Health Care Team } \\
\text { School of Public Health } \\
\text { University of Leeds } \\
\text { Leeds LS2 } 8 L N
\end{array}
$$

1 Storm T, Thamsborg G, Steiniche T, Genant $\mathrm{HK}$, Sorenson OH. Effect of intermittent cyclical etidronate therapy on bone mass and fracture rate in women with postmenopausal osteoporosis. N Engl f Med 1990; 322:1265-71.

2 Watts NB, Harris ST, Genant HK, Wasnich $\mathrm{RD}$, Miller PD, Jackson RD, et al. Intermittent cyclical etidronate treatment of Intermittent cyclical etidronate treatment of
postmenopausal osteoporosis. $N \mathrm{Engl} \mathcal{F} \mathrm{Med}$ postmenopausal oste

3 St Leger AS, Schnieden H, Walsworth-Bell JP. Evaluating health services' effectiveness. Milton Keynes: Open University Press, 1992:127.

4 School of Public Health, University of Leeds; Centre for Health Economics, University of York; Research Unit, Royal College of Physicians; Department of Health. Screening for osteoporosis to prevent fractures. Leeds: for osteoporosis to prevent fractures. Leeds: Care, bulletin No 1.)

5 Purdie DW. Screening for osteoporosis. $\mathrm{Br} \mathcal{F}$ Hosp Med 1992;47:605-8.

6 Fogelman I. Screening for osteoporosis. London: Osteoporosis Screening and Research Unit, Osteoporosis Screening
Guy's Hospital, 1988.

7 Kirkman RJE. Bone density measurement. Lancet 1992;339:371.

8 Holland W, Stewart S. Screening in health care: benefit or bane? London: Nuffield Provincial Hospitals Trust, 1990

\section{Assessing short term outcome}

We were pleased to read the considered evaluation of the Nottingham health profile (NHP) by Bardsley et $a l^{1}$ and impressed with the methodological care which alerted them to the possibility of raised NHP scores resulting from completion of the questionnaire in hospital. The potential for such confounding effects exists in the many research designs which include a comparison of assessments of hospital inpatients and outpatients. Our own longitudinal study of 100 patients with rheumatoid arthritis, which includes $36 \%$ who were first interviewed while hospital inpatients, supports the conclusion of Bardsley et al that the NHP does not seem to be subject to this contamination by a hospital setting. However, we emphasise that this was not the case in our study with another widely used generic questionnaire, the functional limitations profile (FLP). ${ }^{2}$

Factors such as the adoption of a sick role, anxiety about the operation, or the unsettling nature of the environment were cited as potential elevators of NHP scores. Classic psychological literature also indicates that there may be many ways in which setting may influence responses. However, without recourse to sophisticated analysis, we suggest that the impact of hospitalisation on the following selection of items from the FLP is clear: respondents are requested to affirm those statements which apply to them "today" and which are due to their health.

I go out to enjoy myself less often

I lie down to rest more often during the day 
I only get about in one building

I stay in one room

I stay in bed more

I stay in bed most of the time

I do not use public transport now

I do not go into the shopping centre.

I do not go out to visit people at all

I spend most of my time partly dressed or in pyjamas

I do not do any of the clothes washing I would usually do

My sexual activity is decreased.

Lest it should be thought that such items represent no more than "noise" in the background of the scoring system, it should be noted that those of the above list which feature on the mobility domain (one of 12 domains on the FLP) contribute $56 \%$ of that score. If respondents were followed up as outpatients an inappropriate impression of improvement could be gained simply because the respondent is no longer restricted by the requirements of the hospital.

Research designs which involve at least one hospital based completion of a health status measure are widely used. To avoid the danger of results being seriously confounded by setting fellow researchers should be alert to this problem and careful in their selection of questionnaires.

SUE ZIEBLAND RAY FITZPATRICK Department of Health and Primary Care University of Oxford Radcliffe Infirmary,
Oxford

OX2 $6 H E$

CRISPIN JENKINSON Nuffield College,

Oxford

1 Bardsley MJ, Venables CW, Watson J, Goodfellow J, Wright PD. Evidence for validity of a health status measure in assessing short term outcomes of cholecystectomy. Quality in Health Care 1992;1:10-14.

2 Patrick D, Peach H. Disablement in the community. Oxford: Oxford University Press,
1989 .

\section{Improving management of asthma}

I wish to take issue with Bucknall and colleagues in their audit of asthma management. ${ }^{1}$ I suggest that what they showed in their article is a change in care but not necessarily an improvement. Their paper discusses changes in process of management, but this has not been linked to an associated improvement in outcome. I think, therefore, that they are unable to conclude that progress through the audit cycle has been made with positive benefit - this statement cannot be made until improvement in outcome is linked with the change in asthma management.

M A WAITE Queen Elizabeth Medical Centre, Queen Elizabeth Hospital, Birmingham B15 $2 T H$

1 Bucknall CE, Robertson C, Moran F, Stevenson RD. Improving management of asthma: closing the loop or progressing along the audit spiral? Quality in Health Care 1992;1:15-20.
AUTHORS' REPLY - Dr Waite addresses an important issue, one for which we do not have the full answer but which is going to be raised regularly as we learn more about audit and as we attempt to measure outcome. Our recent paper ${ }^{1}$ built on previous work ${ }^{2}{ }^{3}$ in which we showed that the management of asthma was suboptimal in a proportion of patients with asthma. Medical management did not conform to accepted good practice, which has subsequently been defined more explicitly. ${ }^{4}$ Furthermore, when the management of patients admitted under the care of a general medical team, including a respiratory physician, was compared with that of those managed in general medical wards with other specialist interests these differences in management were found to be associated with differences in outcome, although the groups were matched for age, sex, severity of index attack, and previous asthma treatment. We have therefore shown previously that there is a good observational basis for the received wisdom that acute asthma should be managed with oral steroids, oxygen, peak flow recordings, and close supervision after discharge.

The present audit could not determine whether the observed improvement in management (now largely in line with accepted good practice) has led to a better outcome as it was retrospective, but we are currently looking at this. Nevertheless, the audit exercise of asking, "Am I doing what I know is 'right?" (accepted good practice) has had a positive benefit as a better standard of practice has now been achieved.

How improving standards of practice will relate to outcome, however it is defined and measured, is as yet largely virgin territory as the medical input is probably only one factor, along with psychological and social factors, which will influence this. ${ }^{5}$ That is why we need to look at outcomes and learn a great deal more about these relations.

CHRISTINE E BUCKNALI
Greater Glasgow Health Board
Glasgow G4 ORA

1 Bucknall CE, Robertson C, Moran F, Stevenson RD. Improving management of asthma: closing the loop or progressing along the audit spiral? Quality in Health Care 1992;1:15-20.

2 Bucknall CE, Robertson C, Moran F, Stevenson RD. Differences in hospital asthma management. Lancet 1988;i:748-50.

3 Bucknall CE, Robertson C, Moran F, Stevenson RD. Management of asthma in hospital: a prospective audit. BMJ 1988;296: 1637-9.

4 British Thoracic Society. Guidelines for management of asthma in adults. II. Acute management of asthma in adults. II. Acut
severe asthma. BMF 1990;301:797-800.

5 Jones PW. Quality of life measurement for patients with diseases of the airways. Thorax 1991;46:676-82.

\section{British eclampsia survey 1992}

The British eclampsia survey is a descriptive epidemiological study of all cases of eclampsia in the United Kingdom during 1992.

The incidence and case mortality from eclampsia in Britain are not known.
However, eclampsia and pre-eclampsia remain major causes of maternal mortality in the United Kingdom and throughout the rest of the world.

Eclampsia contributes significantly to maternal mortality but it is now relatively rare in the United Kingdom and is encountered by only the busiest UK specialists about once every two years, too infrequently to allow the development of the skills or insights that come with frequent experience. The British Eclampsia Survey Team (BEST) will aggregate the currently scattered experience of specialists to create a corporate body of information on eclampsia which is available to all.

The team will review every case of eclampsia occurring in the United Kingdom during 1992. Notifications of cases of eclampsia are being systematically collected from all obstetric consultants and from a liaison midwife in each obstetric hospital in the United Kingdom. However, the team is also keen to receive notifications from anyone who has been involved in any aspect of the care of women with eclampsia or unexplained seizures in pregnancy during 1992. Maternal health, antenatal care, the features and management of eclampsia, and maternal and fetal outcomes are being analysed from a detailed hospital case note review and from a questionnaire to general practitioners. The incidence of eclampsia and the maternal and perinatal case fatality rates associated with eclampsia are being measured; maternal and perinatal morbidity are being recorded, and specific hypotheses concerning the dangers and preventability of eclampsia are being tested.

The survey is being carried out in association with the new medical audit unit of the Royal College of Obstetricians and Gynaecologists. During the survey the foundations for a continuing national register for auditing eclampsia will be established.

Notification forms and further information about the study can be obtained from BEST, Nuffield Department of Obstetrics and Gynaecology, FREEPOST, John Radcliffe Hospital, Headington, Oxford OX3 9BR (0865 221718).

KIRSTY DOUGLAS BEST,
Nuffield Department of Obstetrics and Gynaecology, fohn Radcliffe Maternity Hospital, Headington, Oxford OX3 9DU

\section{Audit spiral}

The terms cycle and loop have been consistently applied to descriptions of the audit process. Indeed the steps involved that is, evaluation of practice, comparison of practice with an accepted standard, and effecting change to improve practice would follow one another repetitively in any clinical audit process.

That this process is indeed a spiral of repeating cycles has been recognised ${ }^{1}$ even if not widely emphasised and was neatly 